\title{
NONLINEAR BEHAVIOR ANALYSIS OF STEEL BEAMS WITH FLAT OR CORRUGATED WEBS AT ELEVATED TEMPERATURES
}

\author{
Ahmed S. Elamary \\ Structural Department, Faculty of Engineering, Al-azhar University \\ Kena-Egypt
}

(Received March 26, 2008 Accepted April 7, 2008)

\begin{abstract}
At the present the corrugated web beams and the fire action in steel beams are important aspects of structural behavior and are receiving considerable attention from researchers. This paper presents the results of a numerical study, using ANSYS, of the large deflection behavior of steel beams at elevated temperatures with different web shapes; corrugated or flat. A particular emphasis of this paper is to investigate the behavior of steel beams with corrugated web and compare this behavior with flat web beam. After validating the capability of ANASYS against available experimental results of fire tests on restrained steel beams, this paper describes the results of a numerical parametric study. The parameters investigated include beam span, different web shapes (Corrugated/Flat), uniform and non-uniform temperature distributions, different levels of applied load, and effect of lateral torsional buckling. It is concluded that, flat web beams can resist higher than the corrugated web beams at higher level of temperatures. The lateral torsional buckling is the most important factor which should be considered in the design process of the steel beams by checking the beam resistance bending moment capacity in fire. Beams without lateral restrains, affected significantly by the compactness of the web and the flange for the flat and the corrugated web beams respectively. The flange out of plane deflection of the corrugated web beams ( flange transverse bending) is required to be considered in the fire design process.
\end{abstract}

KEYWORDS: Fire resistance; Corrugated Web; Lateral torsional buckling; Steel beams; and Elevated temperatures.

\section{INTRODUCTION}

Webs are one of the main components that act with flanges in hot rolled or built up sections to form beam or girder members. The web may be subjected to elastic buckling from shear, bending moment and localized compressive stresses from reactions or concentrated loads. The interaction between these forms of buckling must be controlled by using transversal and bearing stiffeners as stated in the design codes in case of using flat web. Consequently; the web panels can be considered as stiffened plates that can receive both high shear and high moment in different sections or in the same section depending on the beam statical system. One of the methods of reducing the web thickness without using stiffeners is the use of corrugated sheets as webs. The 
use of corrugated sheets as webs in steel beams instead of regular flat plates with stiffeners has attracted several researches. The application of such beams in actual structures has started since $1960_{\mathrm{s}}$. The failure modes of corrugated web can be summarized as follow:-

(a) Failure of corrugated web under shear; was due to buckling of the web. That buckling of the web is local and global for the coarse and dense corrugations, respectively; Abbas and Elgaaly [1,9] suggested a buckling formulae, which are based on local buckling of the corrugation folds as isotropic flat plates or global buckling of the entire web panel as an orthotropic plate.

(b) Failure of corrugated webs under uniform bending; was sudden and due to vertical buckling of the compression flange into the web after the stress in the flange reached the yield stress. That means, the web offered a negligible contribution to the moment carrying capacity of the beam. Based on these studies, it was concluded that, for design, the ultimate moment capacity can be calculated based on the flange yielding ignoring any contribution from the web; Elgaaly [10].

(c) Failure of corrugated webs under partial compressive edge loading; was due to a flange collapse mechanism and web crippling or web yielding, followed by crippling and vertical bending of the flange into the crippled web; Abbas and Elgaaly [3,11,12]. In additional to the above mentioned modes of failures; Abbas $[2,4,5]$ presented a theoretical formulae for the linear elastic in-plane and torsional behavior of corrugated web I-girders under in-plane loads. Using a typical corrugated web steel I-girder consists of two steel flanges welded to a corrugated steel web. Under a set of simplifying assumptions, Abbas [5] applied the equilibrium of an infinitesimal length of a corrugated web I-girder studied, and the cross-sectional stresses and stress resultants due to primary bending moment and shear were deduced. The analysis show that a corrugated web I-girder can twist out-of-plane simultaneously as it deflects in-plane under the action of in-plane loads. Means that, the corrugated web I-girder under primary moment and shear cannot be analyzed using conventional beam theory alone, and a flange transverse bending analysis is required.

In fire conditions, non of the previous research studied the effect of fire in corrugated web beams in case of protected or unprotected beams. More and over the effect of lateral restrain on the behavior of such type of beams did not consider in most of the research.

The growing use of unprotected or partially protected steelwork in buildings has caused a lively debate regarding the safety of this form of construction. A good deal of recent research has been concentrated in this direction and has indicated that steel members have a substantial inherent ability to resist fire so that additional fire protection can be either reduced or eliminated completely $[14,15]$.

At present, the fire resistant design of a steel beam is based on the bending resistance of the beam [7 and 13]. This resistance is limited to the plastic bending moment capacity or lateral torsional buckling bending capacity of the beam at small deflections. Using this design concept, the steel beam will have a relatively low survival temperature in fire and would require expensive fire protection. Alternative design methods have now become available to eliminate fire protection in many cases, for example by using tensile membrane action [8] in floor slabs or by integrating the functions of load bearing and thermal insulation of concrete [18]. However, 
applications of such alternative methods will still leave the majority of steel beams requiring fire protection.

The fire engineering approach demands a better understanding of the factors which govern the behavior of both individual steel members and the structure as a whole in fire conditions. This control of fire by design and construction is beginning to be a normal method used in building codes to achieve fire safety. It should take into consideration the fact that the basic objective of structural fire safety can be satisfied only if control of the movement of the fire is achieved and if structural stability is provided. When subject to fire, an unprotected steel structure will lose its stiffness and strength as a result of deterioration in its material properties. The traditional approach to this problem has been to design the structure for ambient-temperature strength and serviceability, and then to apply insulation to its load-bearing members to meet the requirements for fire resistance [13]. The prescriptive approach to the design of structural steelwork for fire resistance, which involves the application of a prescribed thickness of fire protection material to limit steel temperatures within required fire resistance periods, is progressively being replaced by a fire engineering approach [6]. This requires the designer to calculate the response of loaded structural elements to increasing temperatures, allowing fire to be considered as one of the limit states for which the structure is initially designed [13].

This paper presents the results of a numerical study, using ANSYS [6], of the deflection behavior of steel beams at elevated temperatures with different web shape. After validating the capability of ANSYS against available experimental results of fire tests on restrained steel beams, this paper describes the results of a numerical parametric study. The parameters investigated include beam span, web shape, uniform and non-uniform temperature distributions, different levels of applied load, and the effect of lateral torsional buckling. The purpose of the present paper is to gain a good understanding of the important parameters that influence of the fire in the steel beam with corrugated web compared with the same beam with flat web.

\section{NUMERICAL SIMULATION METHOD}

In this study, the commercial finite element software, ANSYS, is used. To allow for different loading positions and non-uniform temperature distributions to be considered, shell elements of type SHELL43 in the ANSYS software were used. The finite element simulation for high temperature analysis was divided into two steps, in which the structural load was applied first and then the steel temperatures were increased. During the elevated temperature analysis, the numerical solution process could become unstable. To obtain a stable solution, a pseudo-dynamic procedure was adopted with a dissipated energy fraction of 1E-10. This energy fraction was chosen and recommended by Yin and Wang [18], which is small enough so as to have almost no effect on the deflection behavior of the beam.

\section{MODEL VALIDATION}

The author validated the capability of ANSYS to deal with the steel beams, subjected bending moment and fire, by comparing the performed finite element model with the 
test results on restrained steel beams at large deflections performed by Liu [14]. The test specimens were modeled using finite elements and the computer program ANSYS. The model used to perform nonlinear analysis; the load increments as well as the mesh size were selected based on studies to examine their effects. The comparison between the results obtained from the finite-element analysis and the tests was satisfactory as will be shown in Fig 4.

\subsection{Comparison with test results of Liu et al. [14]}

The tests of Liu et al. [14 and 15], were supported on rollers without axial restraint. Some axially restrained column tests were reported, but they were only concerned with compression induced by restraint to the column's expansion, not tension induced by restraint to the column's shortening. Therefore, this paper only considered the experiments of Liu et al [14 and 15], who conducted a series of fire tests to study the large deflection behavior of restrained steel beams in the Fire Research Laboratory at the University of Manchester. In the test performed the beams, of $178 \times 102 \times 19$ UB (S275) section, were mainly unprotected. In order to simulate the heat-sink effect due to the concrete slab, the top flanges were wrapped with $15 \mathrm{~mm}$ thick ceramic fibre blanket [14]. The steel beam was restrained between two columns to give a structure similar to a rugby goal post as shown in Fig. 1. The goal posts provided the beam with an axial restraint stiffness of $8 \mathrm{kN} / \mathrm{mm}$ [14]. In some tests, additional horizontal restraint was applied at the level of the test beam by struts spanning between the goal post columns to give a total axial restraint of $62 \mathrm{kN} / \mathrm{mm}$ to the beam. Both extended end plate and web cleat beam-to-column connections were tested. The present study only compared numerical simulation results against tests using extended end plate connections, which allowed the test beams to experience some catenary action. The extended end plate connections were estimated to provide a rotational restraint stiffness of $14,000 \mathrm{kNm} / \mathrm{rad}$ to the test beam $[14,18]$. The experimental study considered two different load levels, having a load ratio of 0.5 or 0.7 . The load ratio is defined as the ratio of the applied maximum bending moment in a simply supported beam to the beam's plastic bending moment capacity at ambient temperature.

In numerical simulations, stiff end plates of $10 \mathrm{~mm}$ were attached to the ends of the beam to ensure plane rotation of the beam at ends. The axial restraint to the beam was modelled by an elastic spring of stiffness of 8 or $62 \mathrm{kN} / \mathrm{mm}$. The rotational stiffness of $14,000 \mathrm{kNm} / \mathrm{rad}$ was modelled by two rotational constraints, one between the top flange and the centre, and the other between the bottom flange of the beam and its centre, as shown in Fig. 2, each having a stiffness of $886 \mathrm{kN} / \mathrm{mm}$ [18]. Consequently, the rotational restraints were modeled by using a couple of spring constraints at the top and bottom flanges of the beam end sections, relative to the centre of the beam's cross-section. The experimental measured temperature profiles for flanges and web, shown in Fig. 3, were used in numerical simulations.

In this figure, the results are shown for different level of loading ratio 0.5 and 0.7. It can be seen that the simulation results are in good agreement with the test results, the accuracy of the authors' simulations being comparable to that of the independent study of Liu et al. [14]. 


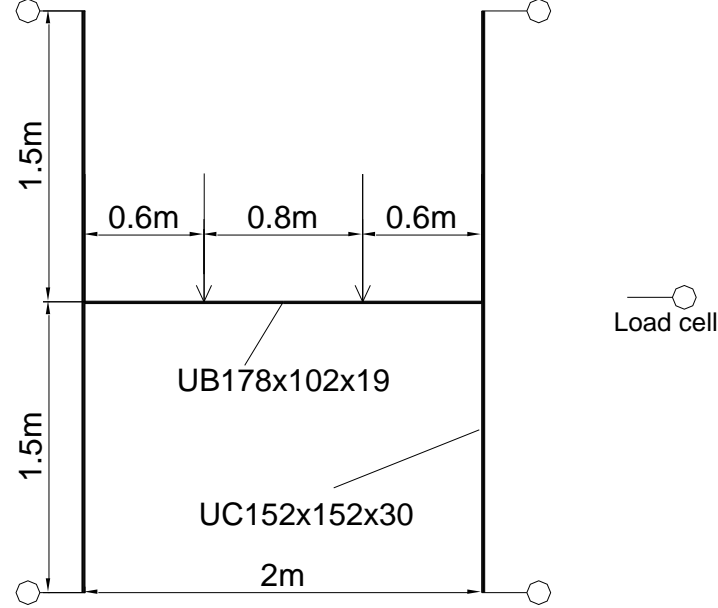

Fig. 1. Schematics of the test arrangement of Liu et al. [14 and 15]

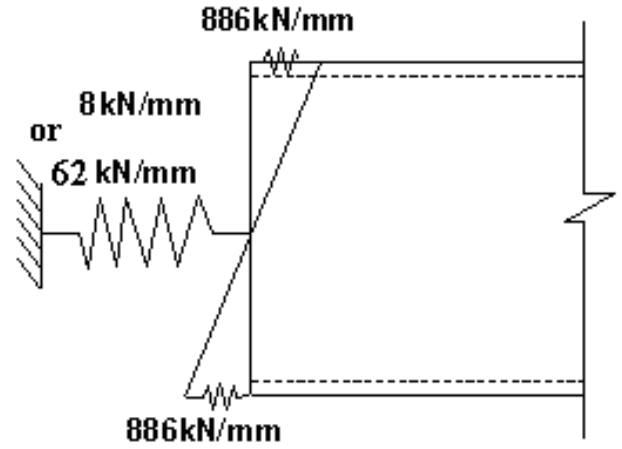

Fig. 2. Application of boundary conditions in numerical simulations of Liu's tests.[14,18]

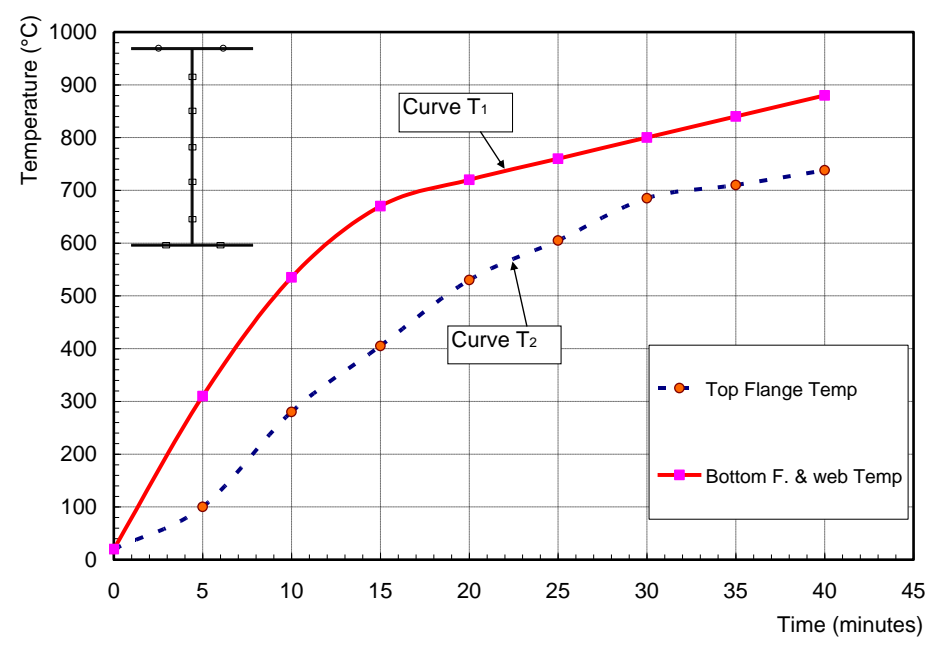

Fig. 3. Measured beam temperature-time relationships from Liu's tests.[14] 


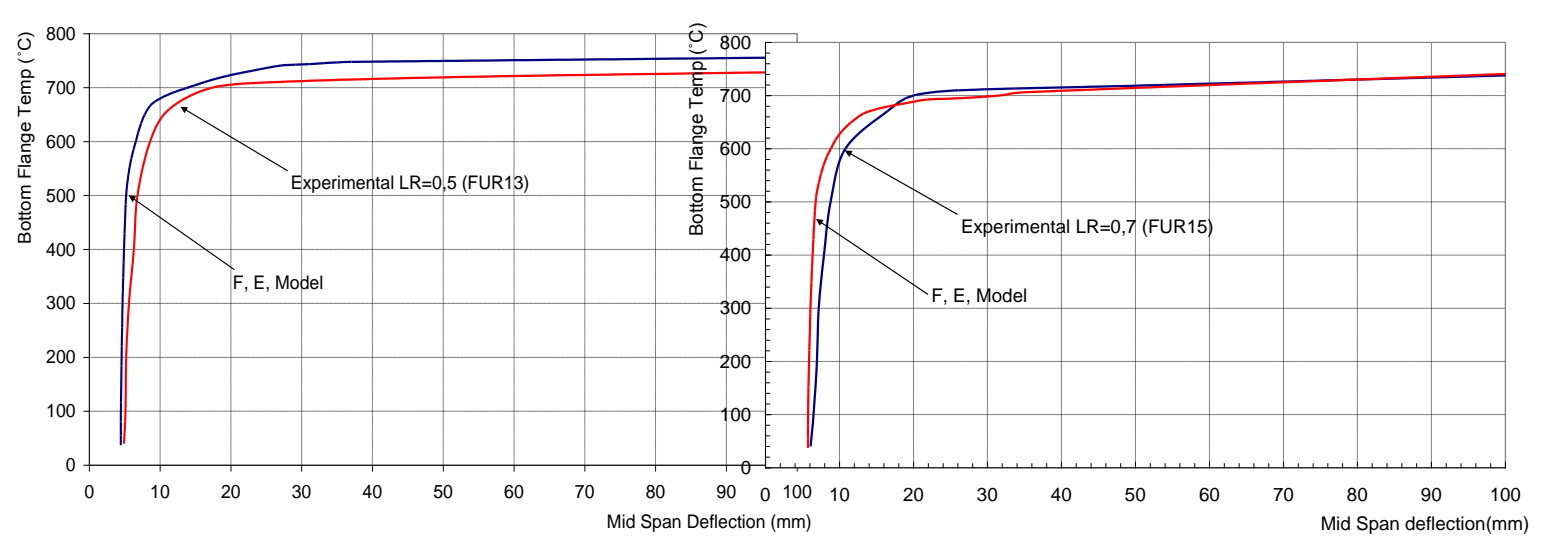

(a) Comparison at 50\% ultimate load resistance

(b) Comparison at $70 \%$ ultimate load resistance

Fig. 4. Comparison between experimental and finite element model.

\section{PARAMETRIC STUDIES}

Testing each assembly for all possible fires is obviously not an economically appealing solution. However, an understanding of the overall behavior of the steel beams with corrugated or flat web in a real fire situation is necessary to increase the efficiency of fire protection. A number of methods have been proposed to calculate the fire resistance of structures under fire conditions, numerical modeling being one of them. The most general and versatile approach is the finite element method, in which various factors affecting the behavior in fire can be included. Among these are non-linear material behavior, geometric non-linearity, and non-uniform temperature distributions. The parametric study is divided into two parts: laterally restrained beams and laterally unrestrained beams. The first part is performed to check various web shapes for the maximum resistance of the steel beam, where the second part conducted to consider the lateral torsional buckling effect. In all cases, the beam is simply supported at both ends and there is no restraint to its thermal expansion. A numerical model represents only a half of the full length of the steel beam, consequently symmetry boundary conditions are used at the beam center in order to simulate the full beam adequately. The main advantage of this method is that it enables the behavior of complicated structures to be studied.

\subsection{Beams and Web configuration:}

The standard beams used in this study are UB457×152×60 and UB406 $\times 178 \times 60$ with a

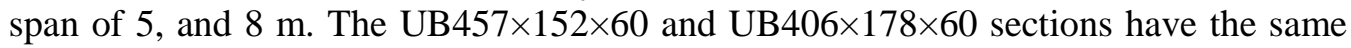
cross-sectional area but different second moments of area. Both of the beams modeled using flat or corrugated web. The dimension of the corrugation profile shown in Fig. 5 is stated in Table 1. 
Table 1. Corrugated dimensions used in this study.

\begin{tabular}{|c|c|c|c|c|c||}
\hline $\begin{array}{c}\mathrm{b} \\
(\mathrm{mm})\end{array}$ & $\begin{array}{c}\mathrm{d} \\
(\mathrm{mm})\end{array}$ & $\begin{array}{c}\mathrm{q} \\
(\mathrm{mm})\end{array}$ & $\begin{array}{c}\mathrm{h}_{\mathrm{r}} \\
(\mathrm{mm})\end{array}$ & $\begin{array}{c}\mathrm{S} \\
(\mathrm{mm})\end{array}$ & $\theta^{\circ}$ \\
\hdashline 200 & 100 & 600 & 100 & 682.8 & 45 \\
\hline
\end{tabular}

S

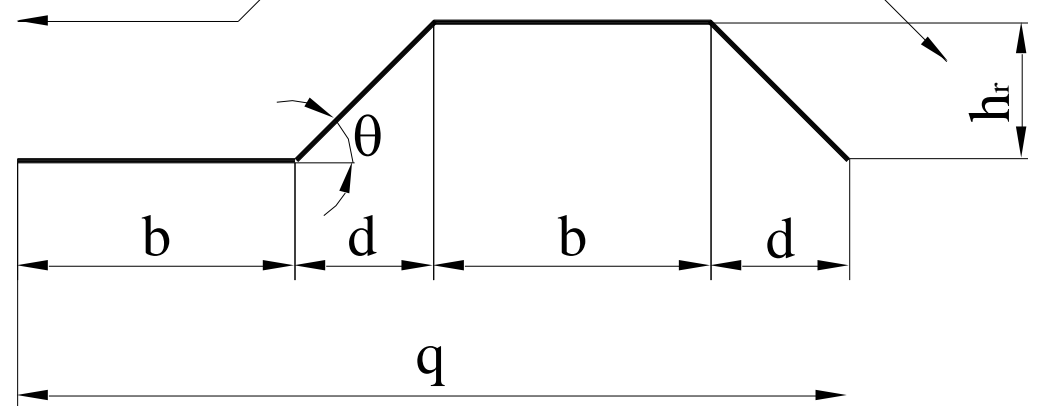

Fig. 5. Profile configuration

\subsection{Temperature distribution and applied load ratios:}

Fig. 6 shows the uniform and a non-uniform temperature distribution which will be used in these analyses. The applied load ratios are 0.4 and 0.7 , defined as the maximum bending moment of a simply supported beam to the yield bending moment capacity of the beam at ambient temperature. A central point load is applied at the top flange and lateral torsional buckling of the beam is restrained. Since, the beam is said to have failed in the fire limit state when the mid span deflection excessed span/20 [18]; consequently, the analysis is performed to pass this limit.
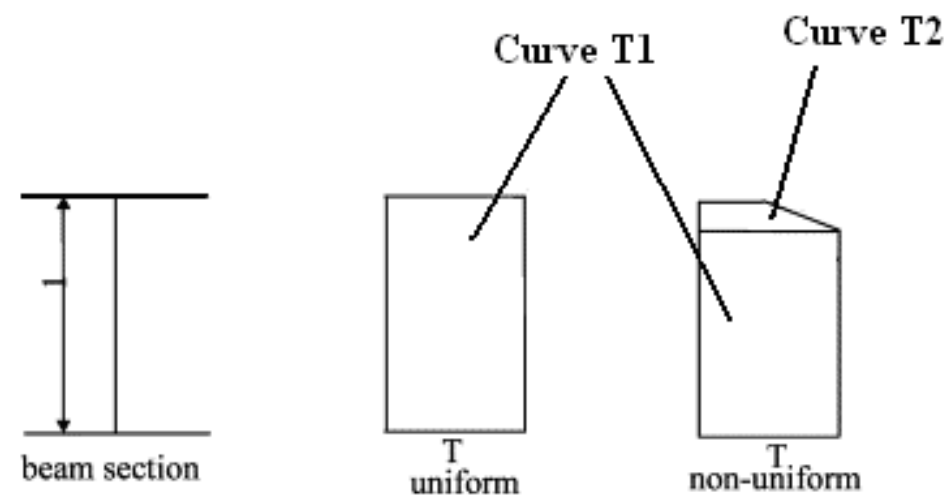

Fig. 6. Temperature profiles. 
The analyses were performed for the UB $457 \times 152 \times 60$ and UB406 $\times 178 \times 60$ beams. The maximum in-plan deflection under central point load and uniform temperature obtained by ANSYS for $8 \mathrm{~m}$ beam with flat web and $5 \mathrm{~m}$ beam with corrugated web shown in Fig. 7. Where, Fig. 8 shows the temperature distribution of $8 \mathrm{~m}$ beam with corrugated web at the end of the analysis if it is subjected to central point load and non-uniform temperature distribution. The results obtained by comparing the temperature-mid span deflection are plotted from Fig. 9 to Fig.12. General comparison between the temperature-deflection curves for all beams under different temperature distributions will be summarized in the upcoming paragraphs. By comparing the beams with the same type of web, it is noticed that at low temperatures, the total deflection of the two beams is different because the beams are in bending and they have significantly different bending moment resistance. At high temperatures when the beams are in catenary action phase they behave almost similarly; because they have the same cross-sectional area. Figs 9 to 12 show also that, the corrugated web beams show higher initial deflection under central load than the flat web beams. The different ranged from $15 \%$ to $20 \%$ for beam UB406 with a span $8 \mathrm{~m}$ and $5 \mathrm{~m}$ respectively; where for beam UB457 the different ranged from $20 \%$ to $25 \%$ for $8 \mathrm{~m}$ and $5 \mathrm{~m}$ span respectively.

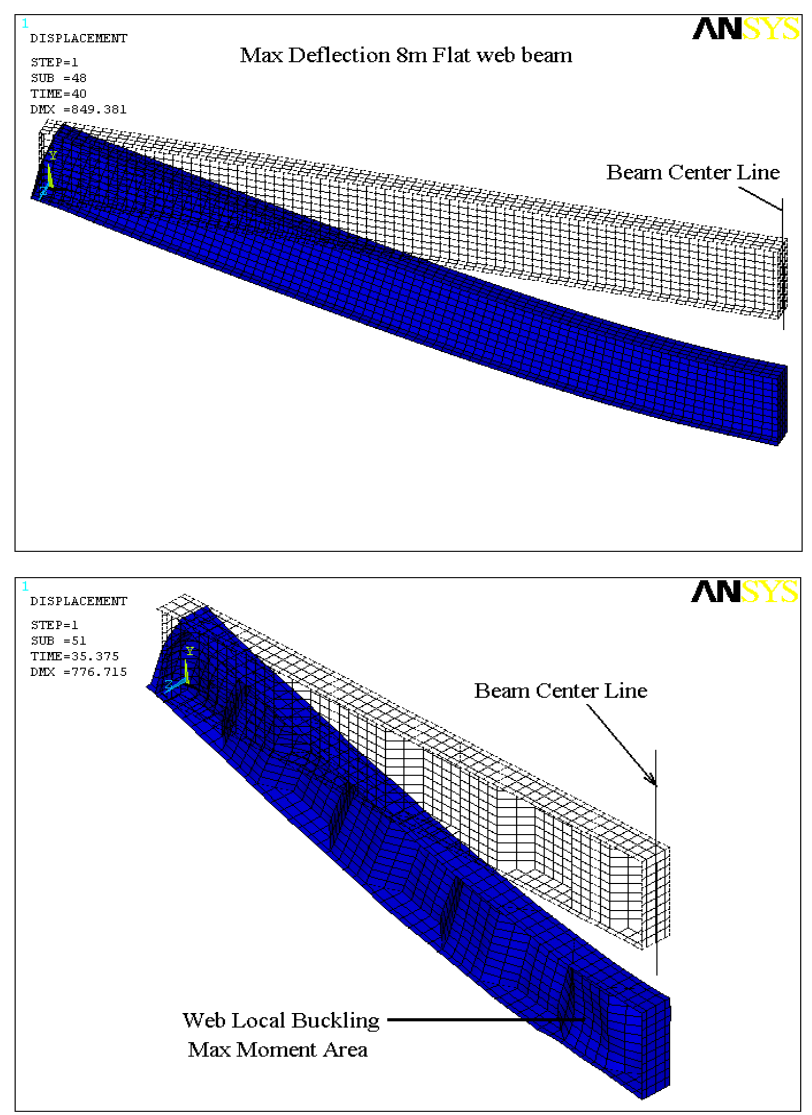

Fig. 7. Deflection shape and the end of the analysis of the Flat and Corrugated web beams 


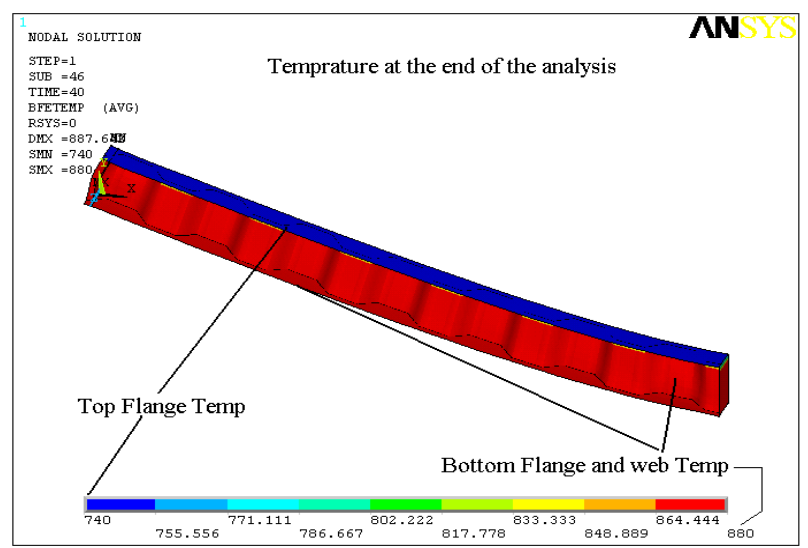

Fig. 8. Non-Uniform Temperature distribution at the end of the analysis for C. web beam

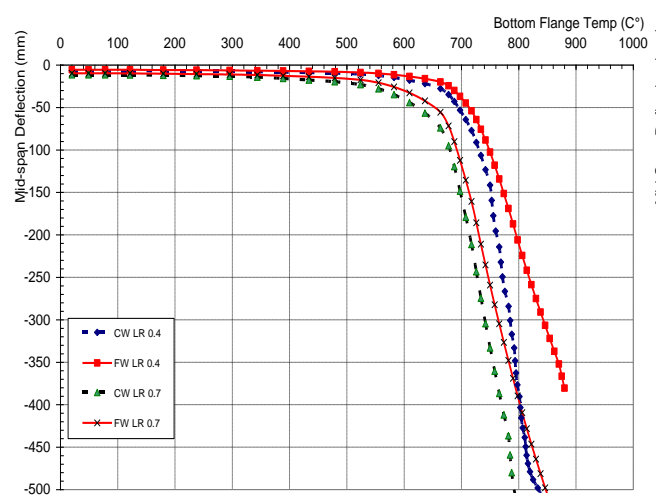

(a) Beam 406 under Non-uniform temperature

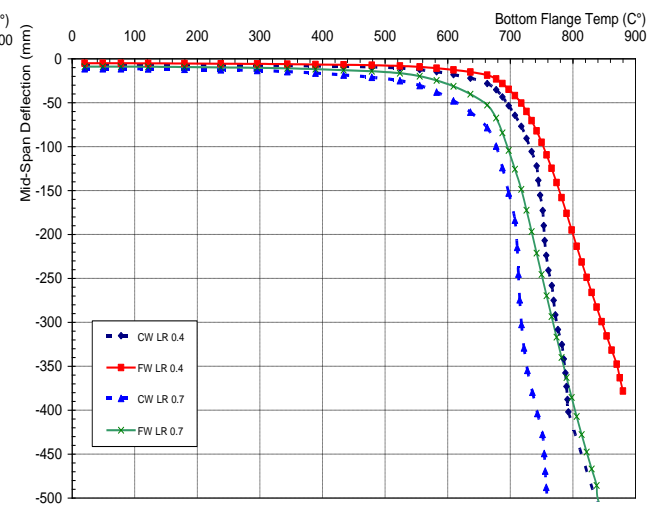

(b) Beam 457 under Non-uniform temperature

Fig. 9. Temperature-deflection relationships of UB457 and UB406 beams, 5m length under non-uniform temperature distribution.

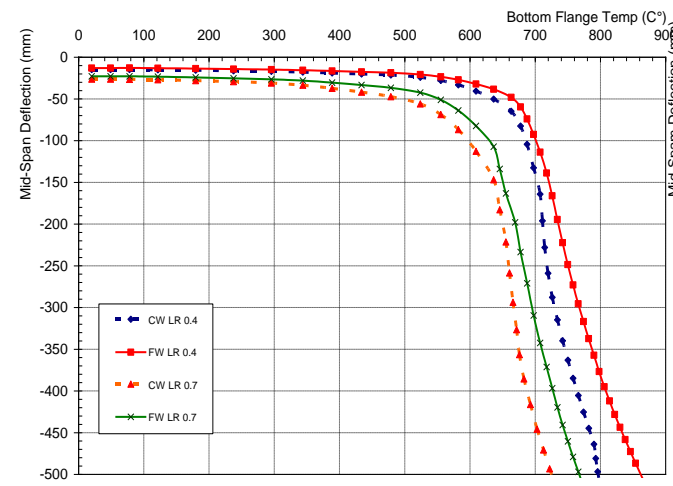

(a) Beam 406 under Non-uniform temperature

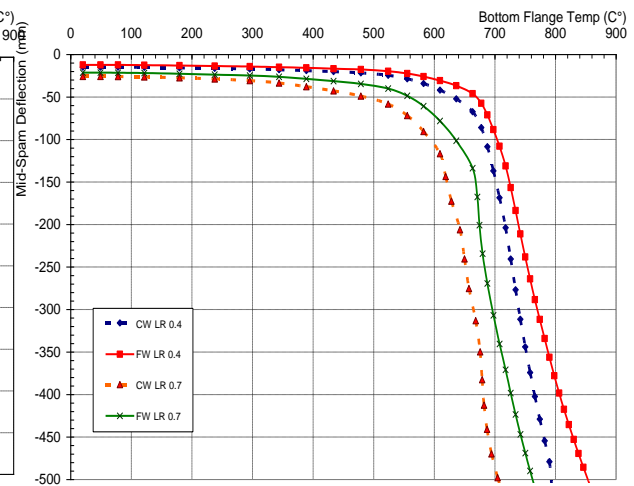

(b)Beam 457 under Non-uniform temperature

Fig. 10. Temperature-deflection relationships of UB457 and UB406 beams, 8m length under non-uniform temperature distribution. 
From the temperature-deflection for the beams with flat or corrugated webs under different temperature distributions, it is observed that the beam deflection vary with the applied load ratio, having larger deflections at a higher load ratio. At low level of temperature the beam's bending moment capacity, which is mainly a function of its temperature distribution, directly controls the beam behavior. Therefore, since the beam behavior is controlled by bending at low temperatures, a longer beam span gives larger beam deflections than the shorter one. Where, at higher temperatures, a beam's bending moment resistance is very small due to the deterioration in the mechanical properties of steel. In additional to, the catenary action phase is started to govern the beam behavior instead of bending moment. In this phase, the deflections of beams of different spans are similar and are mainly dependent on the applied load ratio. More and over, in this phase, it is noticed that, the deflections of beams under uniform temperature distribution are more than those under non-uniform temperature distribution.

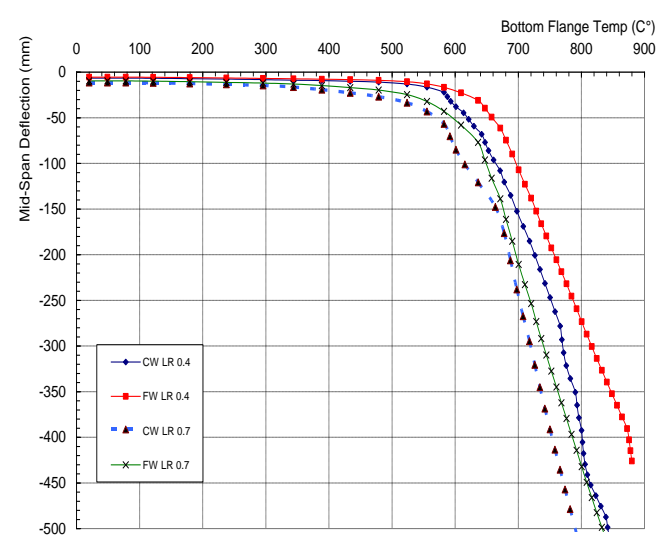

(a) Beam 406 under uniform temperature

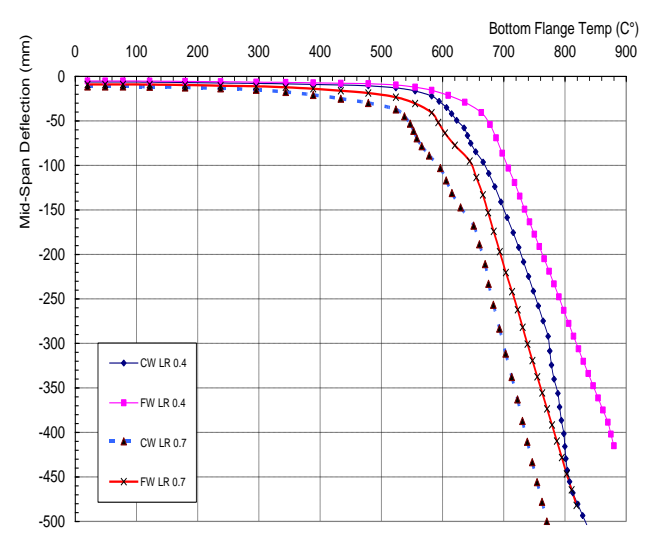

(b) Beam 457 under uniform temperature

Fig. 11. Temperature-deflection relationships of UB457 and UB406 beams, 5m length under uniform temperature distribution.

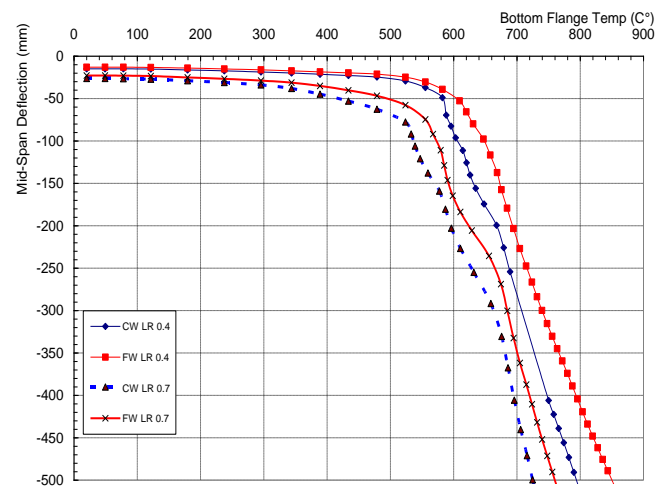

(a) Beam 406 under uniform temperature

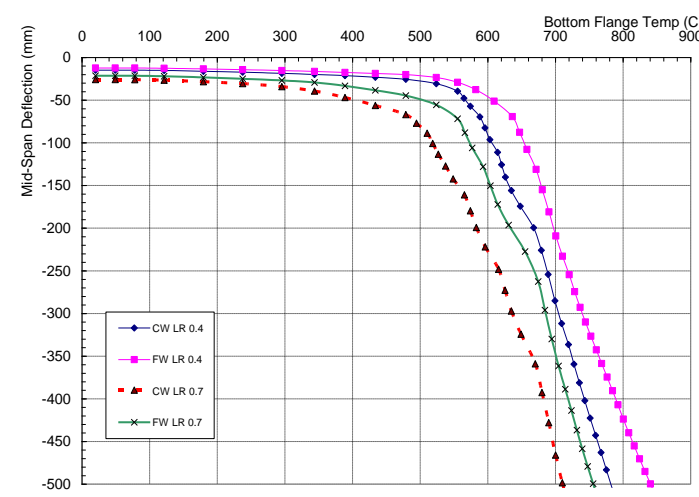

(b) Beam 457 under uniform temperature

Fig. 12. Temperature-deflection relationships of UB457 and UB406 beams, $8 \mathrm{~m}$ length under uniform temperature distribution. 
Table 2 . Temperatures at failed fire limit state (Span/20)

\begin{tabular}{|c|c|c|c|c|c|c|c|c|c|c|c|c|c|c|c|c|}
\hline \multirow{4}{*}{$\begin{array}{c}\text { Axially } \\
\text { and } \\
\text { laterally } \\
\text { restrained }\end{array}$} & \multicolumn{8}{|c|}{ Temp. by $\mathrm{C}^{\circ}$ at deflection $=250 \mathrm{~mm}$} & \multicolumn{8}{|c|}{$\overline{~ T e m p . ~ b y ~} \mathrm{C}^{\circ}$ at deflection $=400 \mathrm{~mm}$} \\
\hline & \multicolumn{4}{|c|}{$\begin{array}{l}\text { Beam 406- } 5 \mathrm{~m} \\
\text { length }\end{array}$} & \multicolumn{4}{|c|}{$\begin{array}{c}\text { Beam } 457-5 \mathrm{~m} \\
\text { length }\end{array}$} & \multicolumn{4}{|c|}{$\begin{array}{l}\text { Beam 406- } 8 \mathrm{~m} \\
\text { length }\end{array}$} & \multicolumn{4}{|c|}{$\begin{array}{c}\text { Beam 457- 8m } \\
\text { length }\end{array}$} \\
\hline & \multicolumn{2}{|c|}{ LR 0.4} & \multicolumn{2}{|c|}{ LR 0.7} & \multicolumn{2}{|c|}{ LR 0.4} & \multicolumn{2}{|c|}{ LR 0.7} & \multicolumn{2}{|c|}{ LR 0.4} & \multicolumn{2}{|c|}{ LR 0.7} & \multicolumn{2}{|c|}{ LR 0.4} & \multicolumn{2}{|c|}{ LR 0.7} \\
\hline & $\mathrm{NU}$ & $\mathrm{U}^{*}$ & $\begin{array}{l}\mathrm{N} \\
\mathrm{U}\end{array}$ & $\mathrm{U}$ & $\begin{array}{l}\mathrm{N} \\
\mathrm{U}\end{array}$ & $\mathrm{U}$ & $\begin{array}{l}\mathrm{N} \\
\mathrm{U}\end{array}$ & $\mathrm{U}$ & $\begin{array}{l}\mathrm{N} \\
\mathrm{U}\end{array}$ & $\mathrm{U}$ & $\begin{array}{l}\mathrm{N} \\
\mathrm{U}\end{array}$ & $\mathrm{U}$ & $\begin{array}{l}\mathrm{N} \\
\mathrm{U}\end{array}$ & $\mathrm{U}$ & $\begin{array}{l}\mathrm{N} \\
\mathrm{U}\end{array}$ & $\mathrm{U}$ \\
\hline \multirow{2}{*}{ F.W } & \multirow{2}{*}{817} & 78 & 74 & 72 & 82 & 79 & 75 & 71 & 80 & 79 & 72 & 71 & 80 & 78 & 72 & 71 \\
\hline & & 5 & 5 & 0 & 0 & 0 & 0 & 5 & 8 & 0 & 5 & 5 & 6 & 6 & 8 & 8 \\
\hline \multirow{2}{*}{ C.W } & \multirow{2}{*}{772} & 75 & 72 & 70 & 76 & 74 & 71 & 68 & 76 & 74 & 68 & 67 & 76 & 74 & 68 & 67 \\
\hline & & 0 & 5 & 0 & 0 & 6 & 5 & 0 & 0 & 5 & 6 & 7 & 0 & 0 & 0 & 0 \\
\hline $\begin{array}{l}\mathrm{U}^{*}= \\
\text { tio }\end{array}$ & & & & & & & & & & & & & & & & \\
\hline
\end{tabular}

Regardless the web shape, if it is assumed that, at the temperature where the beam deflection started to increase rapidly than the temperature increase, is the critical temperatures; then from the above figures it is observed that:-

The two beams UB457 and UB406 show the critical temperature for 5m length under non-uniform temperature $700^{\circ}$ and $650^{\circ}$ corresponding to applied load ratio $0.4 \%$ and $0.7 \%$ from the ultimate capacity respectively. Where, the same beam under uniform temperature distribution, the critical temperatures were $600^{\circ}$ and $550^{\circ}$ corresponding to applied load ratio $0.4 \%$ and $0.7 \%$ respectively. For $8 \mathrm{~m}$ length beams, the critical temperature under non-uniform temperature $650^{\circ}$ and $600^{\circ}$ corresponding to applied load ratio $0.4 \%$ and $0.7 \%$ from the ultimate capacity respectively. Where, the same beam under uniform temperature distribution, the critical temperatures were $550^{\circ}$ and $500^{\circ}$ corresponding to applied load ratio $0.4 \%$ and $0.7 \%$ respectively. In additional to the above mentioned notices, it is observed that, after $500^{\circ}$ and $600^{\circ}$ corresponding to 0.4 and 0.7 load resistance ratio respectively, the behavior showing higher resistance of flat web beam than the corrugated web. The beams at these levels of temperature started to loss their resistance rapidly due to the percentage of decreasing in the modulus of elasticity. Both yield stress and modulus of elasticity after $500^{\circ}$ decreased by significant value which leads to rapidly increasing of the beam deflection. The low resistance of corrugated web due to the decreasing in the flange compactness and both web and flange local buckling in the area close to the mid span. This area has a combine of maximum bending moment and shear. The analyses results summarized in table 1; shows the bottom flange temperatures relevant to span/20 mid span deflection value. From this table it can be noticed that, the effect of applied load ratio, whenever it increased the overall beam resistance under fire conditions decreased significantly. Protection of the top flange from fire can increase the short beam span resistance more than the longer one. Finally, the second moment of inertia of the beams is not effect the ultimate resistance of the beam significantly under fire conditions.

\subsection{Effects of Lateral Torsional Buckling}

Lateral torsional buckling is one of the most important modes of failure of a steel beam at ambient temperature. Consequently, there have been many research studies of this 
topic and it is also comprehensively dealt with in design codes of practice for the ambient temperature condition.

At ambient temperature, occurrence of lateral torsional buckling of a steel beam is often associated with the failure of steel beams where there is not sufficient lateral restraint to the compression flange of the beam. If a steel beam is laterally unrestrained, lateral torsional buckling may occur and this may affect the beam's large deflection behavior. The important of considering the lateral torsional buckling in fire is stated in different codes such as, BS 5950 [7], the slenderness effect is considered in the calculation of load ratio, by dividing the beam's bending moment in fire by the beam's lateral torsional buckling bending resistance at ambient temperature, instead of the beam's plastic bending moment capacity. A similar method is used in ENV 19931.2 [13] in evaluating the critical temperature-utilization factor relationship. In this study, to enable the lateral torsional buckling of a beam to occur, lateral restraints along the beam were removed in numerical simulations and a small lateral deflections were introduced to allow analysis of lateral torsional buckling. Thus each simulation was divided into two steps. In the first step, an eigen-buckling analysis was conducted to identify the critical lateral torsional buckling mode and the associated deflected shape of the beam, which used to specify initial imperfections of the beam. For the present study, the maximum initial imperfections at the centroid of the beam $5 \mathrm{~m}$ and $8 \mathrm{~m}$ beam lengths were $(2.5 \mathrm{~mm}) \mathrm{L} / 2000$ and $(2 \mathrm{~mm}) \mathrm{L} / 4000$ respectively. Since the beams (UB406, UB457) have the same area and length where the only different is the web slenderness ratio, the beam whit less moment of inertia and higher web slenderness (UB406), is analyzed without laterally restrained. The results obtained from the above implied analyses are plotted in figs. 13-a\&13-b, and 14-a\&14-b.

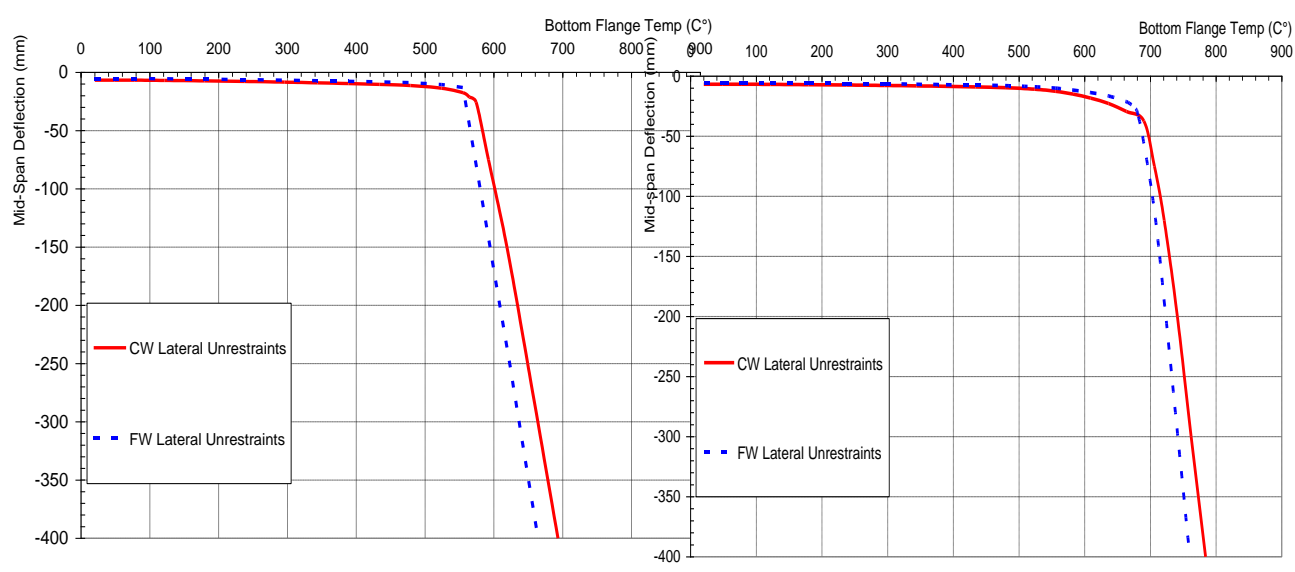

(a) Uniform temperature for F. and C. web beams

(b) Nonuniform temperature for F. and C. web beams

Fig. 13. Temperature-deflection of UB406 beam without lateral restraints, $5 \mathrm{~m}$ Length span. 

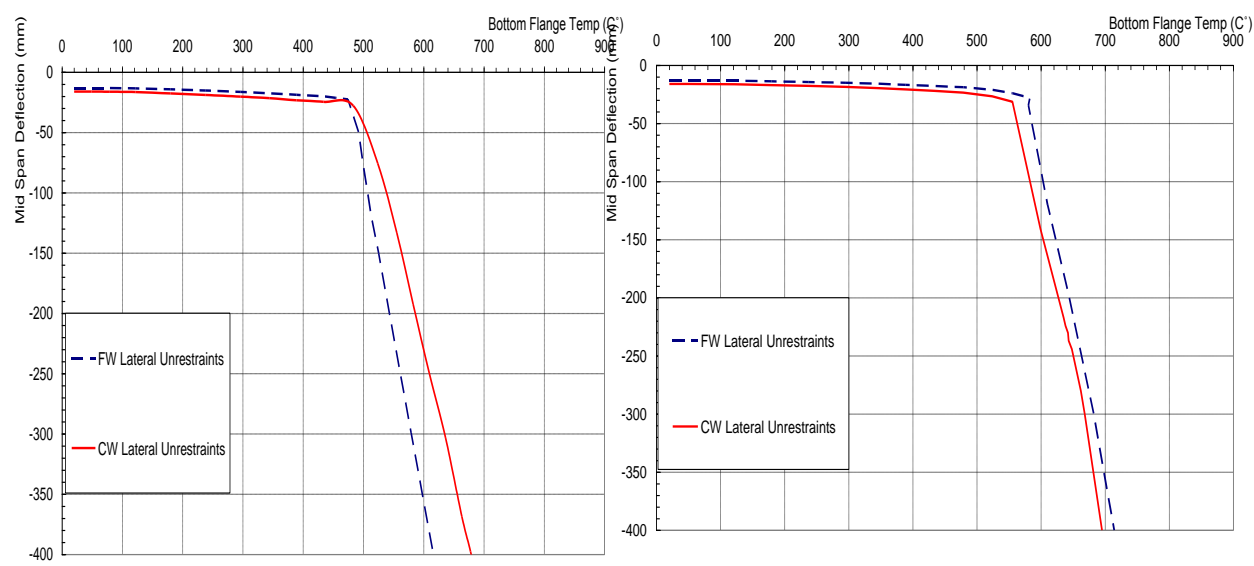

(a) Uniform temperature for F. and C. web beams

(b) Nonuniform temperature for F. and C. web beams

Fig. 14. Temperature-deflection of UB406 beam without lateral restraints, $8 \mathrm{~m}$ Length span.

Figures 13 and 14 show the temperature deflection comparison between corrugated and flat web beams UB406 with $5 \mathrm{~m}$ and $8 \mathrm{~m}$ lengths with initial imperfection $2.5 \mathrm{~mm}$ and $2 \mathrm{~mm}$ respectively. The analysis performed under different conditions of temperatures. It can be seen that, under uniform temperature the corrugated web has a higher resistance than the flat web in spite of it has an initial deflection higher than the flat web. In the other hand, under non-uniform temperatures the beams with both types of web show almost similar behavior. It is noticed that, the corrugated web loose its resistance due to the tow types of flange buckling obtained at the end of the analysis. The first was local flange buckling (due to decreasing of flange compactness) as shown in Fig.15-a where the second was transversal flange buckling (due to variable bearing between flanges and web) which shown in Fig.15-b. Regardless the web shape, again if it is assumed that at the temperature where the beam deflection started to increase rapidly than the temperature increase, is the critical temperatures; then the UB406 show the critical temperature for $5 \mathrm{~m}$ length under nonuniform temperature $700^{\circ}$ and $650^{\circ}$ corresponding to axially and laterally restrained to laterally restrained only respectively. Where, the same beam under uniform temperature distribution, the critical temperatures were $600^{\circ}$ and $550^{\circ}$ corresponding to axially and laterally restrained to laterally restrained only respectively. For $8 \mathrm{~m}$ length under non-uniform temperature $650^{\circ}$ and $580^{\circ}$ corresponding to axially and laterally restrained to laterally restrained only respectively. Where, the same beam under uniform temperature distribution, the critical temperatures were $500^{\circ}$ and $450^{\circ}$ corresponding to axially and laterally restrained to laterally restrained only respectively.

Lateral torsional buckling for both types of $8 \mathrm{~m}$ beams length obtained during the analysis for corrugated or flat web beams shown in Fig 16. 


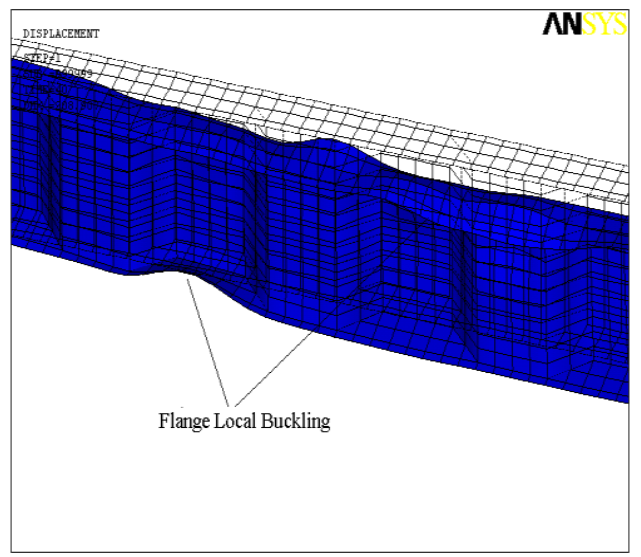

(a) Local flange buckling (in plane)

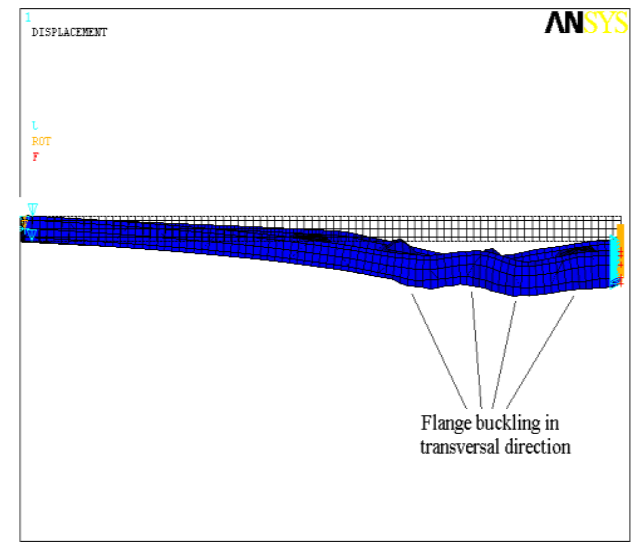

(b) Flange transverse buckling (out of plane)

Fig. 15. Flange buckling in corrugated web beams.
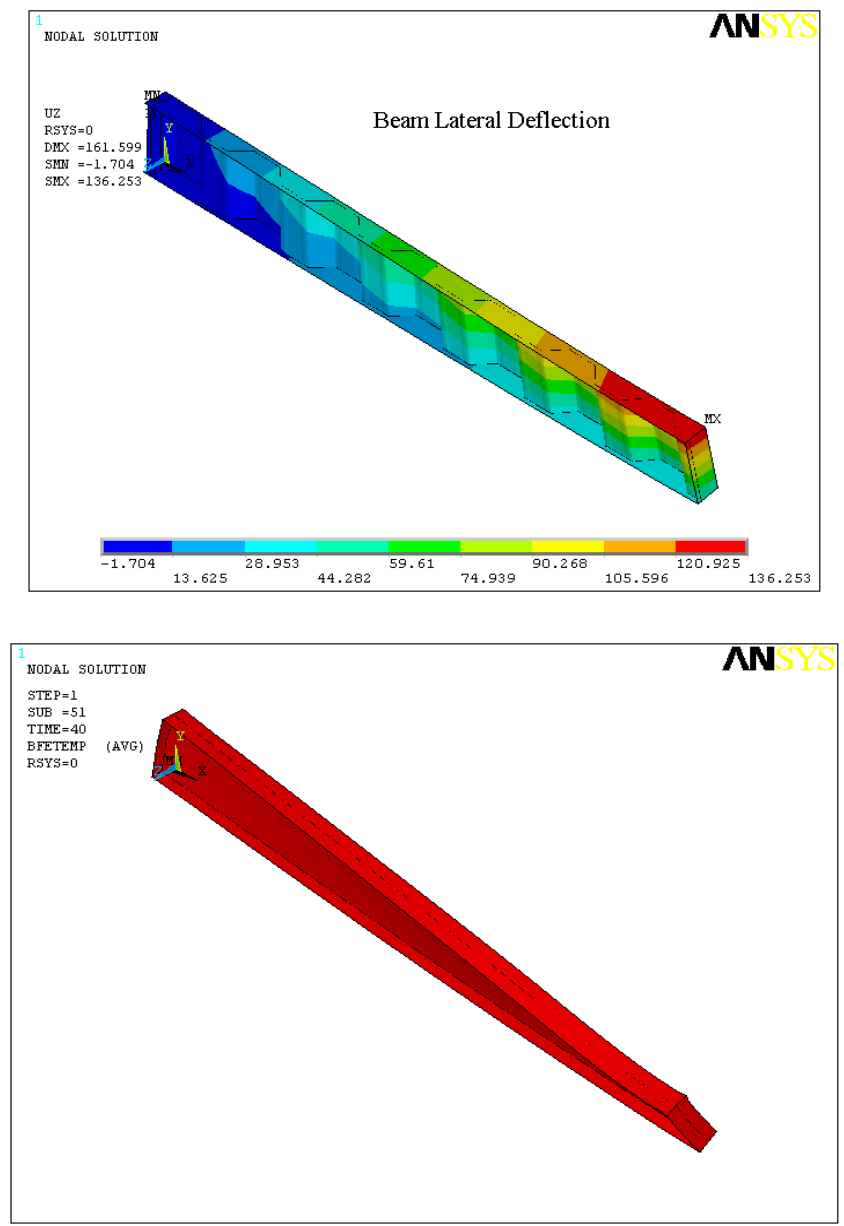

Fig. 16. Lateral torsional buckling for C.W. and F.W. beams $8 \mathrm{~m}$ length. 
Table 3 . Temperatures at failed fire limit state $(\operatorname{Span} / \mathbf{2 0})$

\begin{tabular}{|c|c|c|c|c|c|c|c|c|}
\hline \multirow{3}{*}{$\begin{array}{c}\text { Beam } \\
\text { Length }\end{array}$} & \multicolumn{6}{|c|}{ Temp. by $\mathrm{C}^{\circ}$ at deflection $=250 \mathrm{~mm}$ or $400 \mathrm{~mm}$} \\
\cline { 2 - 9 } & \multicolumn{2}{|c|}{$\begin{array}{c}\text { Beam } 406-5 \mathrm{~m} \text { length }(250 \mathrm{~mm}) \\
\text { laterally } \\
\text { restrained }\end{array}$} & \multicolumn{2}{|c|}{$\begin{array}{c}\text { Axially } \\
\text { restrained }\end{array}$} & \multicolumn{2}{|c|}{$\begin{array}{c}\text { Axially and } \\
\text { laterally } \\
\text { restrained }\end{array}$} & \multicolumn{2}{|c|}{$\begin{array}{c}\text { Axially } \\
\text { restrained }\end{array}$} \\
\cline { 2 - 9 } & $\mathrm{NU}$ & $\mathrm{U}$ & $\mathrm{NU}$ & $\mathrm{U}$ & $\mathrm{NU}$ & $\mathrm{U}$ & $\mathrm{NU}$ & $\mathrm{U}$ \\
\hline \hline \multirow{2}{*}{ F.W } & 817 & 785 & 710 & 620 & 808 & 790 & 700 & 610 \\
\hline C.W & 772 & 750 & 740 & 660 & 760 & 745 & 720 & 680 \\
\hline \hline
\end{tabular}

Table No. 3 shows the temperatures at failed limit state for $5 \mathrm{~m}$ and $8 \mathrm{~m}$ length beam 406 , in case of axially and laterally restrained or only axially restrained boundary conditions. The comparison contains the failed fire limit temperatures under uniform and non-uniform temperatures distribution. From this table, it can be noticed that the resistance of the flat web beams decreased significantly in both cases uniform and nonuniform temperature distributions. Where, in case of corrugated web there is not a great different in case of non-uniform distribution. These cases reflecting the importance of protecting the upper flange which control the behavior of the corrugated web beams. Finally it can be stated that, due to lateral movement of the beam, the bending moment resistance of a beam (using flat or corrugated web configuration) without lateral restraint is lower than a beam with lateral restraints.

\section{CONCLUSIONS}

This paper has presented the results of a numerical study using ANSYS, to analyze the large deflection behavior of steel beams at elevated temperatures with different web shapes. After validating the capability of ANSYS against available experimental results of fire tests for large deflection behavior, a numerical parametric study was conducted and the main conclusions can be drawn as follow;

In case of beams laterally restrained, the flat web beams can resist higher than the corrugated web beams at higher level of temperatures. Beam with lateral restraints can resist the applied load through bending at relatively high temperatures so that catenary action phase occurs at a high temperature. For a beam without lateral restraint, the bending capacity is low so that it goes into catenary action phase at a low temperature.

In case of the beam under uniform heating, where the strength and the stiffness of steel change at the same rate at elevated temperatures, the beam slenderness is unchanged. Consequentially, the beam slenderness changing can be taken into consideration in the calculation of the load ratio in case of non-uniform temperatures distribution effect.

Protect upper flange beam from direct fire can increase the bending resistance of the beam by a significant value. In case of unprotected beams, the lateral torsional buckling is the most important factor which should be taken into consideration in the 
design process of the steel beams using the beam's bending moment capacity in fire. More and over, in case of beams without lateral restrained, the most important factors that govern the overall behavior of the beam are the compactness of the web and the flange for the flat and the corrugated web beams respectively. The out of plane deflection of the corrugated web beams should be considered in the fire design process as one of the important factors.

\section{REFERENCES}

01. Abbas, H.H., Sause, R., and Driver, "Shear Strength and Stability of High Performance Steel Corrugated Web Girders", Proc., Structural Stability Research Council Annual Technical Session, April, Seattle, USA, pp. 361-387 R.G. (2002).

02. Abbas, H.H., "Analysis and Design of Corrugated Web Plate Girder for Bridges Using High Performance Steel", Ph.D. Dissertation, Lehigh University, May 2003.

03. Abbas, H.H., Sause, R., and Driver, "Behavior of corrugated web I-girders under in plane loads" ASCE J. St. Div., Vol. 132 August 2006 pp 806-814

04. Abbas, H.H., Sause, R., and Driver "Analysis of flange transverse bending of corrugated web I-girders under in-plane bending loads" ASCE J. St. Div., Vol. 133 March 2007 pp 347-355

05. Abbas, H.H., Sause, R., and Driver, "Simplified analysis of flange transverse bending of corrugated web I-girders under in-plane moment and shear" Engineering Structures J., Vol. 29 March 2007 pp 2816-2824

06. ANSYS, “standard user's manual”. Ver. 9.(2004)

07. BSI, BS 5950, "Structural use of steelwork in building, part 8, code of practice for fire resistant design. London:" British Standards Institution; 1990.

08. C.G. Bailey and G.N. Newman, "The design of steel framed buildings without applied fire protection". Struct Eng 765 (1998), pp. 77-81.

09. Elgaaly, M., Hamilton R.W. and Seshadri, "Shear Strength of Beams with Corrugated Webs", ASCE J. St. Div., Vol. 122, PP 390- 398, 1996.

10. Elgaaly, M. and Seshadri A, "Bending strength of steel Beams with Corrugated Webs", ASCE J. St. Div., Vol. 123, PP 772- 782, 1997.

11. Elgaaly, M. and Seshadri A, "Girders with corrugated webs under partial compressive edge loading" ASCE J. St. Div., Vol. 123, PP 783- 791, 1997.

12. Elgaaly, M. and Seshadri A, "Depicting the behavior of girders with corrugated webs up to failure using non-linear finite element analysis" Journal of Advances in Engineering Software, Vol. 29, PP 195- 208, 1998.

13. Eurocode 3 "design of steel structures, part 1.2" general rules/structural fire design. European Community for standardization, Brussels, Belgium, 1995.

14. T.C.H. Liu, M.K. Fahad and J.M. Davies, "Experimental investigation of behavior of axially restrained steel beams in fire". J Construct Steel Res 58 (2002), pp. 1211-1230.

15. T.C.H. Liu and J.M. Davies, "Performance of steel beams at elevated temperatures under the effect of axial restraints". Steel Composite Struct 14 (2001), pp. 427-440. 
16. Y.C. Wang, "Steel and composite structures, behavior and design for fire safety". , Spon Press, London (2002).

17. Y.Z. Yin and Y.C. Wang, "Numerical simulations of the effects of non-uniform temperature distributions on lateral torsional buckling of steel I-beams under fire conditions”. J Construct Steel Res 200359 (2003), pp. 1009-1033.

18. Y.Z. Yin and Y.C. Wang, "A numerical study of large deflection behavior of restrained steel beams at elevated temperatures". J Construct Steel Res 60 (2004), pp. 1029-1047.

التحليل اللاخطى لسلوك الكمرات الصلبة ذات الاعصاب الراسية المسطحة او المعرجة تحت تاثير درجات الحرارة العالية

هذا البحث يقدم دراسـه تحليليه باستخدام طريقه العناصـر المحددة وذلك لدراسـه تأثثر درجات الحرارة العاليـة على الكمـرات الصـلبة ذات الاعصـاب الراسـية المعرجـة ومقارنتها بمثيلتها مـن الكمرات ذات الاعصـاب المسطحة. فى هذه الدراسـة تم استخدام برنـامج ANSYS وذلك بعد التحقق من امكانية استخدامه بمقارنة نتائج الموديل بمثيلتها تم تتفيذها عمليا. ثم تطرق البحث الى دراسة عدد من المتغيرات مثل شكل العصب (معرج او مسطح) وطول الكمرهومقدار الحمل المؤثر وتوزيع درجات الحرارة خلال ارتفاع الكمرة واخيرا تأثير انبعاج اللى الجانبى عند تعرض الكمرة الى درجات حرارة عالية. ومن نتائج التحليل العددى التى تم انجازها تم تقديم منحنيات تبادلية بين درجات حرارة الثفه السفلى للكمرة والترخيم فى منتصف البحر • ومن هذا البحث يمكن استتناج ان تغيير شكل العصب ودرجه الحماية ودرجة تقييد الحركة الجانبية لهما تأثير كبير على مقاومة الكمرات الصلبة للحريق. 